\title{
Molecular basis and genetic improvement of economically important traits in aquaculture animals
}

\author{
GUI JianFang ${ }^{*} \&$ ZHU ZuoYan \\ State Key Laboratory of Freshwater Ecology and Biotechnology, Institute of Hydrobiology, Chinese Academy of Sciences, Wuhan 430072, China
}

Received February 24, 2012; accepted February 27, 2012

\begin{abstract}
Aquaculture has been believed to be a major Chinese contribution to the world. In recent 20 years, genome and other genetic technologies have promoted significant advances in basic studies on molecular basis and genetic improvement of aquaculture animals, and complete genomes of some main aquaculture animals have been sequenced or announced to be sequenced since the beginning of this century. Here, we review some significant breakthrough progress of aquaculture genetic improvement technologies including genome technologies, somatic cell nuclear transfer and stem cell technologies, outline the molecular basis of several economically important traits including reproduction, sex, growth, disease resistance, cold tolerance and hypoxia tolerance, and present a series of candidate trait-related genes. Finally, some application cases of genetic improvement are introduced in aquaculture animals, especially in China, and several development trends are highlighted in the near future.
\end{abstract}

aquaculture genome technology, somatic cell nuclear transfer, stem cell technology, reproduction-related gene, sex determination gene, growth-related gene, disease resistance-related genes, cold tolerance-related gene, hypoxia tolerancerelated gene, genetic improvement

Citation: Gui J F, Zhu Z Y. Molecular basis and genetic improvement of economically important traits in aquaculture animals. Chin Sci Bull, 2012, 57: 17511760, doi: 10.1007/s11434- 012-5213-0

Aquaculture has a history of about 4000 years, and China is the earliest country for raising fish in fishponds. However, it is only in the recent 50 years that aquaculture has rapidly developed and become a true production industry because artificial propagation technique has been successfully established since the early 1960 s for the "four important domestic fish" including silver carp, bighead carp, grass carp and black carp [1] and aquaculture biotechnology for genetic breeding and disease control has been quickly developed since the 1980s [2]. In China, the annual aquaculture production capacity has increased to 38.3 million tons in 2010 from less than 1 million tons in 1960s, and possesses the fastest growing rate among agriculture and food industry. The aquaculture proportion has risen to more than $71.3 \%$ of the food fish, and reaches about $70 \%$ of the world's aquaculture production. Aquaculture industry has become a major power to promote sustainable, rapid and stable devel-

*Corresponding author (email: jfgui@ihb.ac.cn) opment of China's fishery, and played an important role in guaranteeing supply, stabilizing the market, ensuring national food security and promoting trade development. As an optimal method for exchanging animal proteins by minimum plant proteins, aquaculture has been believed as the most efficient technology by some authoritative economists, which is a major Chinese contribution to the world.

Just entering the 21 st century, sustainable fisheries have become a common theme for the world, and the effect and contribution of aquaculture on world fish supplies have been widely recognized by many scientists in the developed countries [3,4]. Moreover, fish and other aquatic products as safer food sources have been well identified with most of the people [5]. At the same time, China's aquaculture is in a crucial change stage from traditional farming to modern industry, in which the severely lagged basic research has become the outstanding issue for restricting aquaculture development. Especially, the improved varieties were very few, and major aquaculture fish and shellfish were still de- 
pendent on the wild species. The frequent incidences of infectious diseases led to serious economic losses of about 15 billion RMB annually, and the unreasonable responses and non-standard medication to the diseases further resulted in drug residues, which affected quality and food safety of aquatic products, and in turn restricted the sustainable development of aquaculture [6]. In order to solve the above problems, the National Key Basic Research Program of China (973 Program) has successively supported 7 projects since 1999, such as "Fundamental research on the disease occurrence and disease resistance of the commercially important organisms in mariculture, "Studies on genetic and developmental biological basis for improvement of important aquaculture fishes", "Studies on the disease outbreak and immunological control of commercially important organisms in mariculture", "Investigation of crucial scientific issues in intensive aquaculture of freshwater ponds in China", "Basic studies on functional genomics and molecular design breeding in important aquaculture fishes", "The molecular basis for the important economic traits of the mollusks and the study on the molecular design breeding", and "Basic studies on outbreak mechanism and immunological control of main virus diseases in marine aquaculture animals", which have promoted significant advances in basic studies on genetic improvement and disease control of aquaculture animals. Especially in basic studies on genetic improvement in the aquaculture performance, the molecular basis of several economically important traits including reproduction, sex, growth, disease resistance, cold tolerance, and hypoxia tolerance have begun to elucidate, although these traits are highly complex and problematic. Here, we will attempt to retrace and review some significant breakthrough progress in the field for the recent 10 years, especially the major achievements obtained by Chinese scientists, and attempt to forecast developmental prospects for the future.

\section{Genetic improvement technologies of aqua- culture animals}

\subsection{Aquaculture animals in which complete genomes have been sequenced}

As complete genomes have been sequenced and released from human, model animals and plants, as well as several model fish including zebrafish (Danio rerio), fugu (Fugu rubripes), Tetraodon (Tetraodon nigroviridis), medaka (Oryzias latipes), and three-spined stickleback (Gasterosteus aculeatus) since this century, the genomes of some important aquaculture fish, such as channel catfish (Ictalurus punctatus), Nile tilapia (Oreochromis niloticus), Atlantic salmon (Salmo salar), rainbow trout (Oncorhynchus mykiss), gilthead seabream (Sparus aurata), European seabass (Dicentrarchus labrax), and Atlantic cod (Gadus morhua), have been also sequenced [7,8]. From 2010, the complete genomes of some main aquaculture animals including tongue sole (Cynoglossus semilaevis), Pacific oyster (Crassostrea gigas), large yellow croaker (Pseudosciaena crocea), orange-spotted grouper (Epinephelus coioides), common carp (Cyprinus carpio) and Japanese flounder (Paralichthys olivaceu) have been announced to be sequenced by Chinese fisheries-related institutes (Table 1). In 2011, Institute of Hydrobiology, Chinese Academy of Sciences and the collaborators have also started to sequence the complete genomes of grass carp (Ctenopharyngodon idellus), silver carp (Hypophthalmichthys molitrix) and bighead carp (Aristichthys nobilis) of the "four important domestic fish", and small RNA transcriptomes of bighead and silver carp have been characterized [9]. Therefore, we are convinced that the complete genome bioinformatics and the detailed molecule anatomy will provide significantly referent and even directive knowledge for their trait improvement and disease control of these major aquaculture animals.

\subsection{Genome technologies of aquaculture animals}

In 2007, Prof. Zhanjiang Liu at Auburn University of USA, together with more than 40 aquaculture genomics experts in the world, edited a highly technical and comprehensive book Aquaculture Genome Technologies [10]. According to the book, the major aquaculture genome technologies include DNA marker technologies, such as amplified fragment length polymorphism (AFLP), microsatellites and single nucleotide polymorphism, novel DNA sequencing technologies, such as the SOLiD sequencing platform, the Solexa sequencing platform and the 454 sequencing platform, gene discovery technologies of expressed sequence tags and de novo sequencing of whole transcriptomes, genome mapping technologies, such as genetic linkage mapping, QTL mapping, radiation hybrid mapping and BACbased physical mapping, and genome expression analysis technologies, such as microarray technology and sequence tag-based technology.

Recently, numerous polymorphic DNA markers for aquaculture animals have been developed and significant advances have been made in China. In polyploid gibel carp (Carassius auratus gibelio), several significant molecular markers including transferrin alleles [11], SCAR [12], microsatellites [13], AFLP [14] and mitochondria DNA sequences $[15,16]$ were identified, and dual modes of unisexual gynogenesis and sexual reproduction were revealed by these markers $[17,18]$. Significantly, the unique dual reproduction mode, as commented by Avise (2008), was the first documented instance in vertebrates [19], and the discovery firstly explained reproduction mechanism of high genetic diversity and an evolutionarily long-lived timescale of unisexual species [18]. In common carp (Cyprinus carpio), along with advances of polymorphic markers and genome sequencing, various density linkage maps were constructed 
Table 1 Aquaculture animals that have been announced to be completely sequenced in China

\begin{tabular}{|c|c|c|c|c|}
\hline Species & Genome size & Predicted gene number & Mainly announced institute & Announced time \\
\hline Tongue sole (Cynoglossus semilaevis) & $520 \mathrm{Mb}$ & More than 20000 & $\begin{array}{l}\text { Yellow Sea Fisheries Research Institute, } \\
\text { Chinese Academy of Fishery Sciences }\end{array}$ & August 2010 \\
\hline Pacific oyster (Crassostrea gigas) & $8 \mathrm{~Gb}$ & More than 20000 & $\begin{array}{l}\text { Institute of Oceanology, Chinese Academy of } \\
\text { Sciences }\end{array}$ & August 2010 \\
\hline $\begin{array}{l}\text { Large yellow croaker } \\
\text { (Pseudosciaena crocea) }\end{array}$ & $750 \mathrm{Mb}$ & Data not given & Zhejiang Ocean University & January 2011 \\
\hline $\begin{array}{l}\text { Orange-spotted grouper } \\
\text { (Epinephelus coioides) }\end{array}$ & $1.1 \mathrm{~Gb}$ & More than 20000 & Sun Yat-Sen University & March 2011 \\
\hline Common carp (Cyprinus carpio) & $1.7 \mathrm{~Gb}$ & Data not given & $\begin{array}{l}\text { The Centre for Applied Aquatic Genomics, } \\
\text { Chinese Academy of Fishery Sciences }\end{array}$ & May 2011 \\
\hline $\begin{array}{l}\text { Japanese flounder } \\
\text { (Paralichthys olivaceu) }\end{array}$ & $620 \mathrm{Mb}$ & About 23000 & $\begin{array}{l}\text { Yellow Sea Fisheries Research Institute, Chinese } \\
\text { Academy of Fishery Sciences }\end{array}$ & December 2011 \\
\hline
\end{tabular}

[20-23], and used to locate cold tolerance [20] and muscle fiber-related [22] QTLs. A physical map was constructed from a BAC library containing a total of 92160 BAC clones with an average insert size of $141 \mathrm{~kb}[24,25]$. In addition, a consensus linkage map was also constructed in grass carp [26]. As a required approach for positional gene cloning, physical mapping, and genome sequencing, several BAC libraries have been developed and characterized in other important aquaculture animals of China, such as gibel carp [27], zhikong scallop (Chlamys farreri) [28], pacific white shrimp (Litopenaeus vannamei) [29], grass carp [30], and halfsmooth tongue sole (Cynoglossus semilaevis) [31].

\subsection{Somatic cell nuclear transfer and stem cell tech- nologies in fish}

Nuclear transfer has been successfully applied to fish genetic breeding for about half a century in China [32], and their developmental potentiality and reprogramming have been observed from the transplanted nuclei $[33,34]$. During this century, the cloned zebrafish were obtained by nuclear transfer from long-term-cultured cells [35], and the cytoplasmic impact was analyzed in cross-genus cloned fish derived from transgenic common carp (Cyprinus carpio) nuclei and goldfish (Carassius auratus) enucleated eggs [36]. Moreover, some differentially expressed genes were identified from the cloned zebrafish embryos at the dome stage [37], and the critical developmental stages for high integration efficiency were determined in zebrafish [38,39].

Stem cell culture and application have been rapidly developed in model fishes of medaka and zebrafish [40,41], and some stem cell technologies, such as gene targeting, germ cell transplantation and semi-cloning by nuclear transfer, have been successfully formed because of specific potentials of fish germ stem cells and embryonic stem cells $[42,43]$. Especially, Yi et al. [44] used the semi-cloning technology to create the semi-cloned female medaka which shows normal fertility and germline transmission over three generations. This approach represents a significant development for germline transmission of cultured cells, and will be a potential reproduction technology to combat infertility in vertebrates including human. Additionally, primordial germ cells (PGCs) and spermatogonial stem cells could be transplanted between two different salmonid species, and resulted in production of donor-derived offspring [45-47]. In combination with natural and artificial polyploid fishes with special reproduction modes $[18,48]$, the surrogate approach might have significant values for producing polyploidy stocks in aquaculture or for restoring an endangered species in wild life conservation.

\section{Molecular bases for economic traits of aqua- culture animals}

\subsection{Reproduction trait and candidate reproduction- related genes}

In comparison with mammals, fish reproduction modes and strategies exhibit abundant diversities and extreme particularities [49,50]. Owing to the diversities and particularities, much attention has begun to be paid to some important fish with special reproduction modes. Gibel carp, because of the polyploid background and dual reproduction modes of gynogenesis and sexuality, has become a promising fish for screening and isolating reproduction-related genes that are involved in primordial germ cell formation, oocyte maturation and egg fertilization. Using suppression subtractive hybridization and protein purification [51,52], some important genes, such as germ plasm markers vasa [53] and Dazl [54], oocyte maturation-related factors cyclin A2 [55], C-type lectin [52], Clq-like [56-58], histone H2A variant h2aflo [59], and maternal-effect factor spindlin [60], have been identified and functionally characterized from gibel carp. For example, Sun et al. [61] have observed oocytespecific expression pattern and dynamic distribution of Spindlin during oocyte maturation and egg fertilization, demonstrated its association and interaction with $\beta$-tubulin and spindle, and found that its elimination destroys spindle assembly, and thereby disturbs the oocyte-to-embryo transition and first cleavage, which provided the first direct evidence for the critical oocyte-to-embryo transition function of Spindlin in vertebrates. 
It is well known that fish reproduction is regulated and controlled by a cascade of hormones along the hypothalamus-pituitary-gonad (HPG) axis. In this cascade, gonadotropin-releasing hormones (GnRHs) produced by hypothalamus are found to be the primary neuropeptides, and gonadotropic hormones (GtHs) synthesized and released by pituitary are found to lead ovaries or testicles to produce mature eggs or sperms, whereas dopamine (DA) produced by pituitary has been found to exhibit an inhibiting effect on the functions of GnRHs [62-64]. Multiple GtHs have been reported by Chinese scientists in groupers [65] and Chinese sturgeon (Acipenser sinensis) [66]. In common carp, two GnRH variants have been isolated [67]. Significantly, when common carp sGnRH expression was inhibited by sGnRH antisense, the plasma GtH-II level was significantly reduced, and the gonad development was severely diminished or hampered [68]. Moreover, Xu et al. [69] used the gonad hampered transgenic fish as a model for defining global gene expression changes of the hypothalamic-pituitarygonadal axis, and revealed 9, 28, and 212 differentially expressed genes respectively in hypothalamus, pituitary, and ovary, of which 87 genes were novel. Obviously, this study not only indicated the progressive scaling-up effect of hypothalamic sGnRH antisense acting on the pituitary and ovary, but also provided new insights with respect to the identification of reproduction-related genes and the understanding of the molecular mechanisms and regulative pathways in fish reproduction system. Recently, Zhou et al. (unpublished data) have also conducted a detailed exploration and functional annotation of hypothalamus and pituitary transcriptomes of mature gibel carp by Roche 454 sequencing. By this way, 878430 high quality sequences (average sequence length of (480 \pm 50$) \mathrm{bp}$ ) of hypothalamus and pituitary were assembled into 51111 contigs and 113046 singletons, resulting in 23012 unigenes. Moreover, RNA-Seq approach was applied to analyze the expression level difference of the 23012 unigenes between mature female and male hypothalamus and pituitary. The detailed report will be soon coming.

\subsection{Sex determination and candidate sex determination genes}

Fishes are an attractive group of organisms for studies on vertebrate sex determination, because they include various types of sexuality from hermaphroditism to gonochorism and from environmental to genetic sex determination. Fishes can provide important insight into the plasticity of the sex determination process in vertebrates, and can be used to explore the cascade regulatory pathways and their evolutionary conservation of upstream or downstream function of sex determination genes [70,71]. In 2002, the $D M Y$ gene, a recent duplicate of DMRT1 (Drosophila doublesex and Caenorhabditis mab-3-related transcription factor 1) in the Japanese medaka, was identified as the first sex-determining gene among non-mammalian vertebrates [72], but it was quickly demonstrated that $D M Y$ is not the universal primary sex determining gene in fish [73]. Significantly, DMRT1, the first conserved zinc finger-like DNA binding domain (DM domain) gene identified in vertebrates, has also been shown to be intimately linked to male gonadogenesis and further differentiation among almost all studied fishes including gonochoristic and hermaphroditic species [74]. As a group of protogynous hermaphrodite fishes that the gonad development undergoes transition from ovary to intersexual gonad and then to testis, and cells at different stages during oogenesis and spermatogenesis can be synchronously observed in the transitional gonads, groupers have been used as a good model for mining sex determination or sex differentiation-related genes. Xia et al. [75] have found that grouper DMRT1 is specifically expressed in spermatogenic cells during female-to-male sex reversal, and the spermatogenic cell-specific and dynamic expression pattern was revealed to be basically similar in several sex reversal fishes including protogynous wrasse (Halichoeres tenuispinis) [76] and rice field eel (Monopterus albus) [77] as well as protandrous black porgy (Acanthopagrus schlegeli) [78,79] and gilthead seabream (Sparus aurata) [80].

SOX3 has been suggested to play significant roles in sex determination and differentiation in vertebrates, but the evidence is insufficient and controversial [81]. In grouper gonads, some special cysts synchronously contain primordial germ cells, oogonia and spermatogonia, and SOX3 is expressed very early and can be detected in the nuclei of some primordial germ cells along the germinal epithelium, which provide an excellent chance to examine the functional roles of SOX3. The detailed observation and analysis have indicated that when the SOX3-positive primordial germ cells develop toward oogonia and then oocytes, SOX3 expression continues to increase greatly, whereas, as the SOX3-positive primordial germ cells develop toward spermatogonia, SOX3 expression is stopped and expelled from the nuclei of spermatogonia. The data confirm that SOX3 is involved in oogonium differentiation and oocyte development [82].

In hermaphrodite red-spotted grouper and rice field eel [83,84], the gonad-specific aromatase (cyp19ala) had been also demonstrated to be expressed by follicular cells of follicular layer around oocytes. The promoter activity analysis showed a number of potential binding sites for some transcriptional factors, such as SOX5, GATA gene family, CREB, AP1, FOXL1, C/EBP, ARE and SF-1, and most of the motifs are conserved among the studied fish species. Recently, a hypothesis proposes that the gonadal aromatase upregulation is necessary not only for triggering but also for maintaining ovarian differentiation, and the down-regulation is the only necessary step for inducing a testicular differentiation pathway [85].

Actually, several important genes, such as Fushi Tarazu factor-1 (FTZ-F1), Sry-related HMG-box gene 9 (SOX9), 
Wilms tumor gene 1 (WT1), anti-mullerian hormone $(A M H)$, $D M R T 1$ and the zinc finger transcription factor GATA binding proteins 4 (GATA4), have been supposed as candidate sex determination genes, and a hypothetical regulation hierarchy for sex determination and differentiation has been suggested in the hermaphroditic groupers [86]. In mammals, primary sex determination genes have been divided into 4 classes, in which class I comprises $\mathrm{Y}$ genes that have a male-specific effect required for spermatogenesis, class II are $\mathrm{X}$ genes that are expressed at a higher level in females than in males by virtue of the 2:1 ratio, class III are $\mathrm{X}$ genes that receive a parental imprint, and class IV are sex-specific regions of heterochromatin that exert effects on the epigenetic status of the rest of the genome [87]. Of course, sex determination mechanisms are also intricate in fishes, because fishes, like other aquatic animals of amphibians and reptiles, include male or female heterogametic genetic sex determination with or without strongly differentiated sex chromosomes [88,89]. A recent report indicates that sex-chromosome homomorphy in European tree frogs does not result from a recent turnover but is maintained over evolutionary timescales by occasional $\mathrm{X}-\mathrm{Y}$ recombination, implicating that seemingly ever-young sex chromosomes may thus carry old-established sex-determining genes [90]. Moreover, B chromosomes in addition to standard chromosomes are also found to have a functional effect on sex determination in one cichlid species (Lithochromis rubripinnis) from Lake Victoria [91], which implies that a portion of sex chromosomes has been derived from B chromosomes. Along with the successive revelation of complete genome sequences in some main aquaculture animals and the quick development of next-generation sequencing techniques, more sex determination genes and the underlying mechanisms will be identified and clarified as performed previously in human and chimpanzee [92].

\subsection{Growth trait and candidate growth-related genes}

Growth trait is one of the most valuable traits of interest in genetic improvement of aquaculture animals, because growth rate increase can directly reduce aquaculture costs and lead to the benefit increase. Since growth hormone (GH) gene was identified, many important growth-related genes have been demonstrated to play critical roles in growth regulation of vertebrates. Numerous candidate genes are correlated with growth, including main growth-related genes within the somatotropic axis, such as GH, growth hormone receptor (GHR), insulin-like growth factors (IGF-I and -II), growth hormone-releasing hormone (GHRH), Leptin, and growth hormone inhibiting hormone (GHIH or somatostatin), important transforming growth factor genes expressed in muscle tissues, such as myostatin (MSTN) and myogenic regulatory factors (MRFs), and other possible candidate genes have been recommended in fish through reviewing the livestock and fish literatures [93], and the regulative mechanisms of muscle growth have been explored by introducing different growth models including compensatory growth, genetic manipulation and in vitro tissue culture [94].

Recently, several important growth-related genes have been investigated by Chinese fish endocrinologists. For example, multiple somatostatin and somatostatin receptor genes were characterized in the Chinese sturgeon (Acipenser sinensis) [95] and in groupers [96-99]. Orangespotted grouper orexin was found to be involved in feeding and orexin-A was a stimulator of NPY mRNA expression in vivo and in vitro [100]. Zebrafish ghrelin was demonstrated to play an essential role in GH expression during adenohypophysis development [101]. Follistatin 1 (Fst1) overexpression was revealed to promote muscle growth in the transgenic zebrafish [102].

\subsection{Disease resistance trait and candidate disease re- sistance-related genes}

Along with rapidly growing and highly intensifying in the past 30 years, many aquaculture species have been threatened by some serious diseases caused by viruses, bacteria, fungi, parasites or other undiagnosed and emerging pathogens. Especially in infectious virus diseases, a lot of pathogenic viruses were identified from freshwater and marine culture animals [103], and the complete genomes of several viruses, such as grass carp hemorrhage virus (GCHV) [104], shrimp white spot syndrome virus (WSSV) [105], mandarin fish infectious spleen and kidney necrosis iridovirus (ISKNV) [106], and flounder lymphocystis disease virus isolated in China (LCDV-C) [107], were sequenced in China. Moreover, their structure proteins were characterized [108-111], and some of them were functionally analyzed [112,113].

In order to identify innate antiviral genes that protect fish from some virus infections, suppressive subtractive hybridization technology has been used to isolate virally induced genes from UV-inactivated GCHV-infected CAB cells [114]. Through this model system, a series of interferon (IFN) induced genes have been cloned and characterized, and great progress has been made in identifying fish antidisease genes involved in IFN antiviral response [115-120]. Significantly, some novel interferon-inducible genes have been found [121], and their functional roles and signaling pathways have been well understood in fish [122-124]. Additionally, several candidate genes, such as $P K R$ [125], PKR-like (or called PKZ) [126], $\beta$-Defensin [127], TRBP [128], C-type lectin [129], Enzyme E2 [130], MDA5 and $L G P 2$ [131], have been revealed to play crucial roles in the antiviral defense response of fish and shrimp.

\subsection{Cold tolerance trait and candidate cold tolerance- related genes}

Cold tolerance is an especially attractive trait in fish, and a 
recent experiment evidence suggests that some fishes might carry sufficient genetic variation to adapt to temperature and the cold tolerance should be under strong selection [132]. To identify candidate cold tolerance-related and cold change-related genes, a large-scale EST sequencing of multi-tissues including brain, liver, head kidney, and ovary had been performed in Antarctic notothenioid (Dissostichus mawsoni), and some important cold-specific expressed genes had been identified by comparative transcriptome analyses between $D$. mawsoni and non-notothenioid warm-water teleost fishes [133,134]. Moreover, the molecular origination of antifreeze protein III (AFP III) was demonstrated to come from a duplicate copy of sialic acid synthase (SAS) gene, supporting the evolutionary mechanism by neofunctionalization under escape from adaptive conflict [135].

\subsection{Hypoxia tolerance trait and candidate hypoxia tol- erance-related genes}

Variable hypoxia tolerance has been observed in aquatic animals including reptiles, amphibians, and fishes [136,137], but its molecular mechanisms remain largely unknown. Since Carassius species have been found to survive many days or even several months of anoxia at low temperature, Carassius auratus blastulae embryonic cells have been used to screen gene expression changes responding to hypoxia stress by suppression subtractive hybridization (SSH). Through this approach, a total of 211 differentially expressed genes are identified, in which most of them are reported for the first time from hypoxia-treated teleosts [138].

Moreover, several potential hypoxia tolerance-related genes have been characterized and functionally analyzed in fish. For example, heme oxygenase-1 ( $\mathrm{HOl})$ has been demonstrated to have protective role in fish under hypoxic stress [139]. Grass carp insulin-like growth factor-binding protein 1 (IGFBPI) has been revealed to play a key role in mediating the hypoxia-induced embryonic growth retardation and developmental delay [140]. A novel function of p53 that directly suppresses BNIP3 expression to protect against hypoxia-induced cell death has been found in model fish zebrafish [141]. Also in zebrafish, a stable transgenic fish has been created by expressing the Vitreoscilla hemoglobin (vhb) gene driven by common carp beta-actin promoter, and the expressed $\mathrm{VHb}$ can partially alleviate the hypoxia stress response to improve the survival rate has been confirmed by comparing the expression profiles of the vhb transgenic zebrafish [142].

\section{Application of genetic improvement in aqua- culture animals}

Genome technologies, especially molecular markers, have been designed to apply to breeding program and genetic improvement of main aquaculture animals including rainbow trout, Atlantic salmon, tilapia, channel catfish and ornamental fishes in the world, and their potential values have been evaluated by aquaculture geneticists [49,143-145].

In China, several nuclear genome markers, such as microsatellite patterns, AFLP profiles and transferrin alleles, and one cytoplasmic marker, the whole mitochondrial genome sequence, have been used to identify genetic organization of a novel clone $\mathrm{A}^{+}$created by sexual mating between clone D female and clone A male in polyploid gibel carp [18], which have demonstrated that the novel clone is a nucleo-cytoplasmic hybrid between the known clones A and $\mathrm{D}$, because it contains an entire nuclear genome from the paternal clone A and a mtDNA genome (cytoplasm) from the maternal clone D [146]. Therefore, it is suggested to be formed via androgenesis of clone A sperm in clone D ooplasm. Significantly, the selected nucleo-cytoplasmic hybrid female still maintains its gynogenetic ability, and thereby produces a novel clone variety "CAS III" that has been approved by National Certification Committee for Aquatic Varieties. Owing to the significant growth superiority, the novel clone variety has been propagated by gynogenesis in more than 10 hatcheries, and their offspring have been cultured throughout China [146]. Moreover, the finding will be of great significance for exploiting the genetic breeding approaches in gibel carp [18], because the nucleo-cytoplasmic hybrid clone escapes the genetic and developmental destruction caused by drastic treatments of irradiation and physical shocks in induced androgenesis and nuclear transplantation [146].

Additionally, sex-specific molecule markers have been developed and applied in China. Based on artificial propagation families, and gynogenetic XX, XY and YY individuals obtained previously [147], two pairs of Y chromosome- and $\mathrm{X}$ chromosome-specific markers were isolated from yellow catfish (Pelteobagrus fulvidraco) by AFLP screening, which thereby develops a Y- and X-specific allele marker-assisted sex control technique for mass production of all-male populations [148]. Using this technique, all-male yellow catfish has been approved as a novel variety "yellow catfish all-male No. 1" by National Certification Committee for Aquatic Varieties. Because yellow catfish males grow faster than females, and result in an ultimate size difference of about two to threefold, the all-male yellow catfish has been widely used for commercial production. Recently, all-female flounder has been also recognized as a novel variety for aquaculture in China. According to the developments, we have proposed an integration sex control technique for mass production of all-male populations in aquaculture fish [148]. As shown in Figure 1, the XY physiological females are selected by the $\mathrm{Y}$ chromosome-specific marker (YSM) and X chromosome-specific marker (XSM) from sex reversal progeny through $17 \alpha$-ethinyloestradiol (EE2) treatment, and about $25 \%$ YY super-males can be obtained from the mating progeny of the 

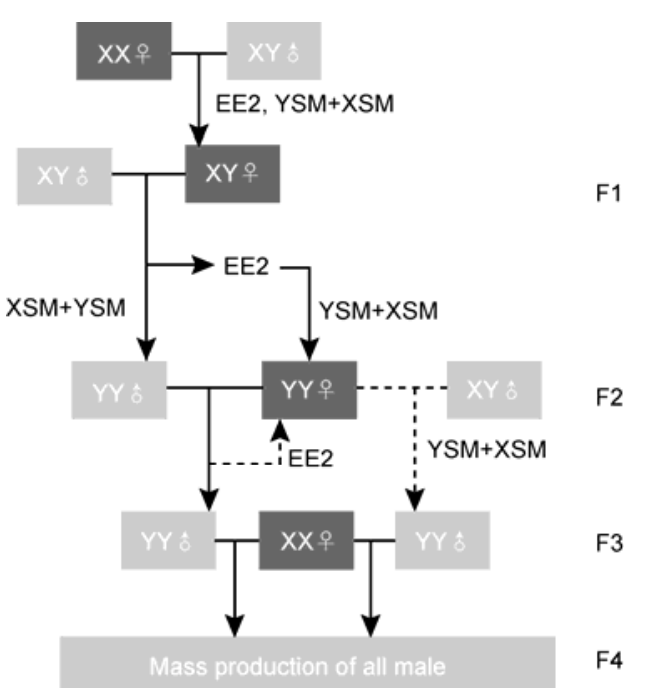

Figure 1 A schematic diagram of mass production of all-male populations through an integration sex control technique of female hormone $17 \alpha$-ethinyloestradiol (EE2) treatment and genetic identification of $\mathrm{Y}$ chromosome-specific marker (YSM) and X chromosome-specific marker (XSM) in aquaculture fish.

reversed XY female and normal XY male by YSM and XSM identification. Then, the YY physiological females can be induced from the EE2 treated YY fingerlings, and YY super-males can be produced continually from the mating of the YY physiological females and YY super-males. Subsequently, the YY super-males can be used to mate with $\mathrm{XX}$ females for commercial mass production of all-XY males.

\section{Conclusion and perspective}

Along with complete genome sequence anatomy of some main aquaculture animals, ongoing development of genome technologies, somatic cell nuclear transfer and stem cell technologies, as well as identification and function analysis of candidate genes relative to economically important traits including reproduction, sex, growth, disease resistance, cold tolerance and hypoxia tolerance, genetic improvement research in aquaculture animals has begun to enter a new era for molecular design breeding. The future issues are mainly aimed at understanding gene regulation and control networks that are related to reproduction, growth, diseaseresistance, cold tolerance and hypoxia tolerance, at identifying the relative functional genes and molecular markers, and at creating novel breeding materials and technologies, which can be used to develop the theoretical strategies and feasible approaches for molecular design breeding in aquaculture animals. It will establish the theoretical and technical foundation for breeding new varieties with high yield and quality, and will make greater contribution for sustainable fisheries and biotechnological innovation.
This work was supported by the National Key Basic Research Program of China (2010CB126301), the Special Fund for Agro-scientific Research in the Public Interest (200903046), and the Autonomous Project of State Key Laboratory of Freshwater Ecology and Biotechnology (2011FBZ17).

1 Wu H W, Zhong L. Progress and achievement on artificial proliferation of grass carp, black carp, silver carp and big head carp in China. Chin Sci Bull, 1964, 9: 900-907

2 Wu C J, Gui J F. Fish Genetics and Breeding Engineering (in Chinese). Shanghai: Shanghai Scientific and Technical Publishers, 1999

3 Naylor R L, Goldburg R J, Primavera J H, et al. Effect of aquaculture on world fish supplies. Nature, 2000, 405: 1017-1024

4 Pauly D, Christensen V, Guénette S, et al. Towards sustainability in world fisheries. Nature, 2002, 418: 689-695

5 James H T, Geoff L A. Fishes as food: aquaculture's contribution. EMBO Rep, 2001, 21: 958-963

6 Gui J F. The present and future of studies on genetic and developmental biological basis for improvement of important aquaculture fishes. Life Sci, 2005, 17: 112-118

7 Sarropoulou E, Nousdili D, Magoulas A, et al. Linking the genomes of nonmodel teleosts through comparative genomics. Mar Biotechnol, 10: 227-233

8 Star B, Nederbragt A J, jentoft S, et al. The genome sequence of Atlantic cod reveals a unique immune system. Nature, 2011, 477: 207-210

9 Chi W, Tong C, Gan X, et al. Characterization and comparative profiling of MiRNA transcriptomes in bighead carp and silver carp. PLoS ONE, 2011, 6: e23549

10 Liu Z J. Aquaculture Genome Technologies. Oxford, UK: Blackwell Publishing, Ames, IA, 2007

11 Yang L, Gui J F. Positive selection on multiple antique allelic lineages of transferrin in the polyploid Carassius auratus. Mol Biol Evol, 2004, 21: 1264-1277

12 Zhou L, Wang Y, Gui J F. Molecular analysis of silver crucian carp (Carassius auratus gibelio Bloch) clones by SCAR markers. Aquaculture, 2001, 201: 219-228

13 Guo W, Gui J F. Microsatellite marker isolation and cultured strain identification in Carassius auratus gibelio. Aquaculture Int, 2008, 16: 497-510

14 Wang D, Mao H L, Peng J X, et al. Discovery of a male-biased mutant family and identification of a male-specific SCAR marker in gynogenetic gibel carp Carassius auratus gibelio. Prog Nat Sci, 2009, 19: 1537-1544

15 Li F B, Gui J F. Clonal diversity and genealogical relationships of gibel carp in four hatcheries. Anim Genet, 2008, 39: 28-33

16 Jakovlic I, Gui J F. Recent invasion and low level of divergence between diploid and triploid forms of Carassius auratus complex in Croatia. Genetica, 2011, 139: 789-804

17 Zhou L, Wang Y, Gui J F. Genetic evidence for gonochoristic reproduction in gynogenetic silver crucian carp (Carassius auratus gibelio Bloch) as revealed by RAPD assays. J Mol Evol, 2000, 51: 498-506

18 Gui J F, Zhou L. Genetic basis and breeding application on clonal diversity and dual reproduction modes in polyploid Carassius auratus gibelio. Sci China Life Sci, 2010, 53: 409-415

19 Avise J C. Clonality: The Genetics, Ecology, and Evolution of Sexual Abstinence in Vertebrates. USA: Oxford University Press, 2008

20 Sun X W, Liang L Q. A genetic linkage map of common carp ( $C y$ prinus carpio L.) and mapping of a locus associated with cold tolerance. Aquaculture, 2004, 238: 165-172

21 Cheng L, Liu L, Yu X, et al. A linkage map of common carp (Cyprinus carpio) based on AFLP and microsatellite markers. Anim Genet, 2009, 41: 191-198

22 Zhang Y, Xu P, Lu C, et al. Genetic linkage mapping and analysis of muscle fiber-related QTLs in common carp (Cyprinus carpio L.). Mar Biotechnol, 2010, 13: 376-392

23 Zheng X, Kuang Y, Zhang X, et al. A genetic linkage map and comparative genome analysis of common carp (Cyprinus carpio L.) using microsatellites and SNPs. Mol Genet Genomics, 2011, 286: 261-277 
24 Li Y, Xu P, Zhao Z X, et al. Construction and characterization of the BAC library for common carp Cyprinus Carpio L. and establishment of microsynteny with Zebrafish Danio Rerio. Mar Biotechnol, 2010, 13: 706-712

$25 \mathrm{Xu} \mathrm{P}$, Li J, Li Y, et al. Genomic insight into the common carp ( $C y$ prinus carpio) genome by sequencing analysis of BAC-end sequences. BMC Genomics, 2011, 12: 188

26 Xia J H, Liu F, Zhu Z Y, et al, A consensus linkage map of the grass carp (Ctenopharyngodon idella) based on microsatellites and SNPs. BMC Genomics, 2010, 11: 135

27 Geng F S, Zhou L, Gui J F. Construction and characterization of a BAC library for Carassius auratus gibelio, a gynogenetic polyploid fish. Anim Genet, 2005, 36: 535-536

28 Zhang Y, Zhang X, Scheuring C F, et al. Construction and characterization of two bacterial artificial chromosome libraries of Zhikong scallop, Chlamys farreri Jones et Preston, and identification of BAC clones containing the genes involved in its innate immune system. Mar Biotechnol, 2008, 10: 358-365

29 Zhang X, Zhang Y, Scheuring C, et al. Construction and characterization of a bacterial artificial chromosome (BAC) library of Pacific white shrimp, Litopenaeus vannamei. Mar Biotechnol, 2010, 12: 141-149

30 Jang S H, Liu H, Su J G, et al. Construction and characterization of two bacterial artificial chromosome libraries of grass carp. Mar Biotechnol, 2010, 12: 261-266

31 Shao C W, Chen S L, Scheuring C F, et al. Construction of two BAC libraries from half-smooth tongue sole Cynoglossus semilaevis and identification of clones containing candidate sex-determination genes. Mar Biotechnol, 2010, 12: 558-568

32 Yan S Y, Lu D Y, Du M, et al. Nuclear transplantation in teleosts. Hybrid fish from the nucleus of crucian and the cytoplasm of carp. Sci Sin B. 1984, 27: 1029-1034

33 Chen H, Yi Y, Chen M, et al. Studies on the developmental potentiality of cultured cell nuclei of fish. Int J Biol Sci, 2010, 6: 192-198

34 Deng C, Liu H. An unknown piece of early work of nuclear reprogramming in fish eggs. Int J Biol Sci, 2010, 6: 190-191

35 Lee K Y, Huang $\mathrm{H}$, Ju B, et al. Cloned zebrafish by nuclear transfer from long-term-cultured cells. Nat Biotechnol, 2002, 20: 795-799

36 Sun Y H, Chen S P, Wang Y P, et al. Cytoplasmic impact on crossgenus cloned fish derived from transgenic common carp (Cyprinus carpio) nuclei and goldfish (Carassius auratus) enucleated eggs. Biol Reprod, 2005, 72: 510-515

37 Luo D, Hu W, Chen S, et al. Identification of differentially expressed genes between cloned and zygote-developing zebrafish (Danio rerio) embryos at the dome stage using suppression subtractive hybridization. Biol Reprod, 2009, 80: 674-684

$38 \mathrm{Hu} \mathrm{W}$, Zhu Z Y. Integration mechanisms of transgenes and population fitness of GH transgenic fish. Sci China Life Sci, 2010, 53: 401408

39 Luo D J, Hu W, Chen S P, et al. Critical developmental stages for the efficiency of somatic cell nuclear transfer in zebrafish. Int J Biol Sci, 2011, 7: 476-486

40 Hong Y, Liu T, Zhao H, et al. Establishment of a normal medakafish spermatogonial cell line capable of sperm production in vitro. Proc Natl Acad Sci USA, 2004, 101: 8011-8016

41 Hong N, Li Z, Hong Y. Fish Stem Cell Cultures. Int J Biol Sci, 2011, 7: 392-402

42 Xu H, Li M, Gui J, et al. Fish germ cells. Sci China Life Sci, 2010, 53: 435-446

43 Yi M, Hong N, Li Z, et al. Medaka fish stem cells and their applications. Sci China Life Sci, 2010, 53: 426-434

44 Yi M, Hong N, Hong Y. Generation of medaka fish haploid embryonic stem cells. Science, 2009, 326: 430-433

45 Takeuchi Y, Yoshizaki G, Takeuchi T. Biotechnology: Surrogate broodstock produces salmonids. Nature, 2004, 430: 629-630

46 Okutsu T, Suzuki K, Takeuchi Y, et al. Testicular germ cells can colonize sexually undifferentiated embryonic gonad and produce functional eggs in fish. Proc Natl Acad Sci USA, 2006, 103: 27252729
47 Okutsu T, Shikina S, Kanno M, et al. Production of trout offspring from triploid salmon parents. Science, 2007, 317: 1517

48 Liu S. Distant hybridization leads to different ploidy fishes. Sci China Life Sci, 2010, 53: 416-425

49 Gui J F. Genetic Basis and Artificial Control of Sexuality and Reproduction in Fish (in Chinese). Beijing: Science Press, 2007

50 Jalabert B. Particularities of reproduction and oogenesis in teleost fish compared to mammals. Reprod Nutr Dev, 2005, 45: 261-279

51 Xie J, Wen J J, Chen B, et al. Differential gene expression in fully grown oocytes between gynogenetic and gonochoristic crucian carps. Gene, 2001, 271: 109-116

52 Dong C H, Yang S T, Yang Z A, et al. A C-type lectin associated and translocated with cortical granules during oocyte maturation and egg fertilization in fish. Dev Biol, 2004, 265: 341-354

$53 \mathrm{Xu} \mathrm{H} \mathrm{Y,} \mathrm{Gui} \mathrm{J} \mathrm{F,} \mathrm{Hong} \mathrm{Y} \mathrm{H.} \mathrm{Differential} \mathrm{expression} \mathrm{of} \mathrm{vasa} \mathrm{RNA}$ and protein during spermatogenesis and oogenesis in the gibel carp (Carassius auratus gibelio), a bisexually and gynogenetically reproducing vertebrate. Dev Dyn, 2005, 233: 872-882

54 Peng J X, Xie J L, Zhou L, et al. Evolutionary conservation of Dazl genomic organization and its continuous and dynamic distribution throughout germline development in gynogenetic gibel carp. J Exp Zool Part B, 2009, 312B: 855-871

55 Xie J, Wen J J, Yang Z A, et al. Cyclin A2 is differentially expressed during oocyte maturation between gynogenetic silver crucian carp and gonochoristic color crucian carp. J Exp Zool, 2003, 295: 1-16

56 Chen B, Gui J F. Identification of a novel C1q family member in color crucian carp (Carassius auratus) ovary. Comp Biochem Phys B, 2004, 138: 285-293

57 Mei J, Chen B, Yue H M, et al. Identification of a C1q family member associated with cortical granules and follicular cell apoptosis in Carassius auratus gibelio. Mol Cell Endocrinol, 2008, 289: 67-76

58 Mei J, Zhang Q Y, Li Z, et al. C1q-like inhibits p53-mediated apoptosis and controls normal hematopoiesis during zebrafish embryogenesis. Dev Biol, 2008, 319: 273-284

$59 \mathrm{Wu}$ N, Yue H M, Chen B, et al. Histone H2A has a novel variant in fish oocytes. Biol Reprod, 2009, 81: 275-283

60 Wang X L, Sun M, Mei J, et al. Identification of a Spindlin homolog in gibel carp (Carassius auratus gibelio). Comp Biochem Physiol B Biochem Mol Biol, 2005, 141: 159-167

61 Sun M, Li Z, Gui J F. Dynamic distribution of spindlin in nucleoli, nucleoplasm and spindle from primary oocytes to mature eggs and its critical function for oocyte-to-embryo transition in gibel carp. J Exp Zool, 2010, 313A: 461-473

62 Mylonas C C, Fostier A, Zanuy S. Broodstock management and hormonal manipulations of fish reproduction. Gen Comp Endo, 2010, 165: 516-534

63 Zohar Y, Muñoz-Cueto J A, Elizur A, et al. Neuroendocrinology of reproduction in teleost fish. Gen Comp Endocrinol, 2010, 165: 438-455

$64 \mathrm{Li} \mathrm{W} \mathrm{S}$, Lin H R. The endocrine regulation network of growth hormone synthesis and secretion in fish: Emphasis on the signal integration in somatotropes. Sci China Life Sci, 2010, 53: 462-470

65 Li C J, Zhou L, Wang Y, et al. Molecular and expression characterization of three gonadotropin subunits common $\alpha, \mathrm{FSH} \beta$ and $\mathrm{LH} \beta$ in groupers. Mol Cell Endocrinol, 2005, 233: 33-46

66 Cao H, Zhou L, Zhang Y Z, et al. Molecular characterization of Chinese sturgeon gonadotropins and cellular distribution in pituitaries of mature and immature individuals. Mol Cell Endocrinol, 2009, 303: 34-42

$67 \mathrm{Li} \mathrm{S}, \mathrm{Hu} \mathrm{W}$, Wang Y, et al. Cloning and expression analysis in mature individuals of two chicken type-II GnRH (cGnRH-II) genes in common carp (Cyprinus carpio). Sci China Ser C-Life Sci, 2004, 47: 349-358

$68 \mathrm{Hu} \mathrm{W}$, Li S, Tang B, et al. Antisense for gonadotropinreleasing hormone reduces gonadotropin synthesis and gonadal development in transgenic common carp (Cyprinus carpio). Aquaculture, 2007, 271: 498-506

$69 \mathrm{Xu} \mathrm{J}$, Huang W, Zhong C, et al. Defining global gene expression changes of the hypothalamic-pituitary-gonadal axis in female 
sgnrh-antisense transgenic common carp (Cyprinus carpio). PLoS ONE, 2011, 6: e21057

70 Brunner B, Hornung U, Shan Z, et al. Genomic organization and expression of the double-sex related gene cluster in vertebrates and detection of putative regulatory regions for DMRT1. Genomics, 2001, 77: $8-17$

71 Delvin R H, Nagahama Y. Sex determination and sex differentiation in fish. Aquaculture, 2002, 208: 191-364

72 Matsuda M, Nagahama Y, Shinomiya A, et al. DMY is a Y-specific DM-domain gene required for male development in the medaka fish. Nature, 2002, 417: 559-663

73 Volff $\mathrm{J}$ N, Kondo M, Schartl M. Medaka dmY/dmrt1Y is not the universal primary sex-determining gene in fish. Trends Genet, 2003, 19: 196-199

74 Herpin A, Schartl M. Dmrt1 genes at the crossroads: a widespread and central class of sexual development factors in fish. FEBS J, 2011, 278: 1010-1019

75 Xia W, Zhou L, Yao B, et al. Differential and spermatogenic cellspecific expression of DMRT1 during sex reversal in protogynous hermaphroditic groupers. Mol Cell Endocrinol, 2007, 263: 156-172

76 Jeong H B, Park J G, Park Y J, et al. Isolation and characterization of DMRT1 and its putative regulatory region in the protogynous wrasse, Halichoeres tenuispinis. Gene, 2009, 438: 8-16

77 Huang X, Guo Y, Shui Y, et al. Multiple alternative splicing and differential expression of dmrt1 during gonad transformation of the rice field eel. Biol Reprod, 2005, 73: 1017-1024

78 He C L, Du J L, Wu G C, et al. Differential Dmrt1 transcripts in gonads of theprotandrous black porgy, Acanthopagrus schlegeli. Cytogenet Genome Res, 2003, 101: 309-313

79 Wu G C, Chiu P C, Lin C J, et al. Testicular dmrt1 is involved in the sexual fate of the ovotestis in the protandrous black porgy. Biol Reprod, 2012, 86: 41

80 Liarte S, Chaves-Pozo E, Garcia-Alcazar A, et al. Testicular involution prior to sex change in gilthead seabream is characterized by a decrease in DMRT1 gene expression and by massive leukocyte infiltration. Reprod Biol Endocrinol, 2007, 5: 20

81 Graves J A M. Weird animal genomes and the evolution of vertebrate sex and sex chromosomes. Annu Rev Genet, 2008, 42: 565-586

82 Yao B, Zhou L, Wang Y, et al. Differential expression and dynamic changes of SOX3 during gametogenesis and sex inversion in protogynous hermaphroditic fish. J Exp Zool, 2007, 307A: 207-219

83 Huang W, Zhou L, Li Z, et al. Expression pattern, cellular localization and promoter activity analysis of ovarian aromatase (Cyp19a1a) in protogynous hermaphrodite red-spotted grouper. Mol Cell Endocrinol, 2009, 307: 224-236

84 Zhang Y, Zhang W, Yang H, et al. Two cytochrome P450 aromatase genes in the hermaphrodite rice field eel Monopterus albus: mRNA expression during ovarian development and sex change. J Endocrinol, 2010, 199: 317-331

85 Guiguen Y, Fostier A, Piferrer F, et al. Ovarian aromatase and estrogens: a pivotal role for gonadal sex differentiation and sex change in fish. Gen Comp Endocrinol, 2010, 165: 352-366

86 Zhou L, Gui J F. Molecular mechanisms underlying sex change in hermaphroditic groupers. Fish Physiol Biochem, 2010, 36: 181-193

87 Arnold A P. The end of gonad-centric sex determination in mammals. Trends Genet, 2012, 28: 55-61

88 Quinn A E, Sarre S D, Ezaz T, et al. Evolutionary transitions between mechanisms of sex determination in vertebrates. Biol Lett, 2011, 7: 443-448

89 Mank J E. Small but mighty: the evolutionary dynamics of W and Y sex chromosomes. Chromosome Res, 2012, 20: 21-33

90 Stöck M, Horn A, Grossen C, et al. Ever-young sex chromosomes in European tree frogs. PLoS Biology, 2011, 9: e1001062

91 Yoshida K, Terai Y, Mizoiri S, et al. B chromosomes have a functional effect on female sex determination in lake victoria cichlid fishes. PLoS Genet, 2011, 7: e1002203

92 Hughes J F, Skaletsky H, Pyntikova T, et al. Chimpanzee and human $\mathrm{Y}$ chromosomes are remarkably divergent in structure and gene content. Nature, 2010, 463: 536-539
93 De-santis C, Jerry D R. candidate growth genes in finfish-Where should we be looking? Aquaculture, 2007, 272: 22-38

94 Johnston I A, Bower N I, Macqueen D J. Growth and the regulation of myotomal muscle mass in teleost fish. J Exp Biol, 2011, 214: 1617-1628

$95 \mathrm{Li} \mathrm{C} \mathrm{J,} \mathrm{Wei,} \mathrm{Q} \mathrm{W,} \mathrm{et} \mathrm{al.} \mathrm{Molecular} \mathrm{and} \mathrm{expression} \mathrm{characterization} \mathrm{of}$ two somatostatin genes in the Chinese sturgeon, Acipenser sinensis. Comp Biochem Physiol A Mol Integr Physiol, 2009, 154: 127-134

96 Ye X, Li W S, Lin H R. Polygenic expression of somatostatin in orange-spotted grouper (Epinephelus coioides): molecular cloning and distribution of the mRNAs encoding three somatostatin. Mol Cell Endocrinol, 2005, 241: 62-72

97 Zhang L, Li W S, Hong X, et al. Regulation of preprosomatostatin I (PSSI) gene expression by $17 \beta$-estradiol and identification of the PSSI promoter region in orange-spotted grouper (Epinephelus coioides). Mol Cell Endocrinol, 2009, 311: 87-93

98 Liu Y, Lu D, Zhang Y, et al. The evolution of somatostatin in vertebrates. Gene, 2010, 463: 21-28

99 Dong H, Li W, Lin H. Comparative analyses of sequence structure, evolution, and expression of four somatostatin receptors in orange-spotted grouper (Epinephelus coioides). Mol Cell Endocrinol, 2010, 323: 125-136

100 Yan A F, Zhang L J, Tang Z G, et al. Orange-spotted grouper (Epinephelus coioides) orexin: Molecular cloning, tissue expression, ontogeny, daily rhythm and regulation of $N P Y$ gene expression. Peptides, 2011, 32: 1363-1370

$101 \mathrm{Li} \mathrm{X}, \mathrm{He} \mathrm{J}, \mathrm{Hu} \mathrm{W}$, et al. The essential role of endogenous ghrelin in growth hormone expression during zebrafish adenohypophysis development. Endocrinol, 2009, 150: 2767-2774

$102 \mathrm{Li} \mathrm{X}, \mathrm{He} \mathrm{J}, \mathrm{Hu} \mathrm{W}$, et al. Enhanced hyperplasia in muscles of transgenic zebrafish expressing Follistatin 1. Sci China Life Sci, 2011, 54: 159-165

103 Zhang Q Y. A review of viral diseases of aquatic in China. Acta Hydrobiol Sin, 2002, 26: 93-101

104 Qiu T, Lu R H, Zhang J, et al. Complete nucleotide sequence of the S10 genome segment of grass carp reovirus (GCRV). Dis Aqua Org, 2001, 44: 69-74

105 Yang F, He J, Lin X H, et al. Complete genome sequence of the shrimp white spot bacilliform virus. J Virol, 2001, 75: 11811-11820

106 He J G, Deng M, Weng S P, et al. Complete genome analysis of the mandarin fish infectious spleen and kidney necrosis iridovirus. Virology, 2001, 291: 126-139

107 Zhang Q Y, Xiao F, Xie J, et al. Complete genome sequence of lymphocystis disease virus (LCDV-C) isolated from China. J Virol, 2004, 78: 6982-6994

108 Xie X X, Xu L M, Yang F. Proteomic analysis of the major envelope and nucleocapsid proteins of white spot syndrome virus. J Virol, 2006, 80: 10615-10623

109 Zhou Q, Xu L, Li H, et al. Four major envelope proteins of white spot syndrome virus bind to form a complex. J Virol, 2009, 83: 47094712

110 Zhao Z, Ke F, Huang Y H, et al. Identification and characterization of a novel envelope protein in Rana grylio virus. J Gen Virol, 2008, 89: 1866-1872

111 Dong C F, Xiong X P, Shuang F, et al. Global landscape of structural proteins of infectious spleen and kidney necrosis virus. J Virol, 2011, 85: 2869-2877

112 Zhao Z, Shi Y, Ke F, et al. Constitutive expression of thymidylate synthase from LCDV-C induces a transformed phenotype in fish cells. Virology, 2008, 372: 118-126

113 Wang Z L, Xu X P, He B L, et al. Infectious spleen and kidney necrosis virus ORF48R functions as a new viral vascular endothelial growth factor. J Virol, 2008, 82: 4371-4383

114 Zhang Y B, Zhang Q Y, Xu D Q, et al. Identification of antiviralrelevant genes in the cultured fish cells induced by UV-inactivated virus. Chin Sci Bull, 2003, 48: 581-588

115 Zhang Y B, Gui J F. Molecular characterization and IFN signal pathway analysis of Carassius auratus CaSTAT1 identified from the cultured cells in response to virus infection. Dev Comp Immunol, 
2004, 28: 211-227

116 Zhang Y B, Gui J F. Identification and expression analysis of two IFN-inducible genes in crucian carp (Carassius auratus L.). Gene, 2004, 325: 43-51

117 Hu C Y, Zhang Y B, Huang G P, et al. Molecular cloning and characterization of a fish PKR-like gene from the cultured CAB cells induced by UV-inactivated virus. Fish Shellfish Immunol, 2004, 17: 353-366

118 Zhang Y B, Jiang J, Chen Y D, et al. The Innate Immune Response to Grass Carp Haemorrhagic Virus (GCHV) in Cultured Carassius auratus Blastulae (CAB) Cells. Dev Comp Immunol, 2007, 31: 232243

119 Zhang Y B, Wang Y L, Gui J F. Identification and characterisation of two homologs of interferon stimulated gene ISG15 in crucian carp. Fish Shellfish Immunol, 2007, 23: 52-61

120 Shi Y, Zhang Y B, Zhao Z, et al. Molecular characterization and subcellular localization of Carassius auratus interferon regulatory factor-1. Dev Comp Immunol, 2008, 32: 134-146

121 Jiang J, Zhang Y B, Li S, et al. Expression regulation and functional characterization of a novel interferon-inducible gene Gig2 and its promoter. Mol Immunol, 2009, 46: 3131-3140

122 Yu F F, Zhang Y B, Liu T K, et al. Fish virus-induced interferon exerts antiviral function through Stat1 pathway. Mol Immunol, 2010, 47: 2330-2341

123 Sun F, Zhang Y B, Liu T K, et al. Characterization of fish IRF3 as an IFN-inducible protein reveals evolving regulation of IFN response in vertebrates. J Immunol, 2010, 185: 7573-7582

124 Sun F, Zhang Y B, Liu T K, et al. Fish MITA activation serves as a mediator for distinct fish IFN gene activation dependent on IRF3 or IRF7. J Immunol, 2011, 187: 2531-2539

125 Zhu R, Zhang Y B, Zhang Q Y, et al. Functional domains and the antiviral effect of the double-stranded RNA-dependent protein kinase PKR from Paralichthys olivaceus. J Virol, 2008, 82: 6889-6901

126 Liu T K, Zhang Y B, Liu Y, et al. Cooperative roles of fish PKZ and PKR in IFN-mediated antiviral response. J Virol, 2011, 85: 12769_ 12780

127 Jin J Y, Zhou L, Wang Y, et al. Antibacterial and antiviral roles of a fish $\beta$-defensin expressed both in pituitary and testis. PLoS ONE, 2010, 5: e12883

128 Wang S, Liu N, Chen A J, et al. TRBP homolog interacts with eukaryotic initiation factor 6 (eIF6) in Fenneropenaeus chinensis. J Immunol. 2009, 182: 5250-5258

129 Zhao Z Y, Yin Z X, Xu X P, et al. A novel C-type lectin from the shrimp Litopenaeus vannamei possesses anti-white spot syndrome virus activity. J Virol, 2009, 83: 347-356

130 Chen A J, Wang S, Zhao X F, et al. Enzyme E2 from Chinese white shrimp inhibits replication of white spot syndrome virus and ubiquitinates its RING domain proteins. J Virol, 2011, 85: 8069-8079

131 Chang M, Collet B, Nie P, et al. Expression and functional characterization of the RIG-I-like receptors MDA5 and LGP2 in Rainbow trout (Oncorhynchus mykiss). J Virol, 2011, 85: 8403-8412

132 Barrett R D, Paccard A, Healy T M, et al. Rapid evolution of cold tolerance in stickleback. Proc Biol Sci, 2011, 278: 233-238

133 Chen Z, Cheng $\mathrm{C} \mathrm{H}$, Zhang J, et al. Transcriptomic and genomic evolution under constant cold in Antarctic notothenioid fish. Proc Natl Acad Sci USA, 2008, 105: 12944-12949

$134 \mathrm{Xu} \mathrm{Q}$, Cheng $\mathrm{C} \mathrm{H}, \mathrm{Hu}$, et al. Adaptive evolution of hepcidin genes in antarctic notothenioid fishes. Mol Biol Evol, 2008, 25: 1099-1112

135 Deng C, Cheng C H, Ye H, et al. Evolution of an antifreeze protein by neofunctionalization under escape from adaptive conflict. Proc Natl Acad Sci USA, 2010, 107: 21593-21598

136 Bickler E, Buck T. Hypoxia tolerance in reptiles, amphibians, and fishes: life with variable oxygen availability. Annu Rev Physiol, 2007, 69: $145-170$

137 Lushchak V I. Adaptive response to oxidative stress: Bacteria, fungi, plants and animals. Comp Biochem Physiol C Toxicol Pharmacol, 2011, 153: 175-190

138 Zhong X P, Wang D, Zhang Y B, et al. Identification and characterization of hypoxia-induced genes in Carassius auratus blastulae embryonic cells using suppression subtractive hybridization. Comp Biochem Physiol B, 2009, 152: 161-170

139 Wang D, Zhong X P, Qiao Z X, et al. Inductive transcription and protective role of fish heme oxygenase-1 under hypoxic stress. J Exp Biol, 2008, 211: 2700-2706

140 Sun C F, Tao Y, Jiang X Y, et al. IGF binding protein 1 is correlated with hypoxia-induced growth reduce and developmental defects in grass carp (Ctenopharyngodon idellus) embryos. Gen Comp Endocrinol, 2011, $172:$ 409-415

141 Feng X, Liu X, Zhang W, et al. p53 directly suppresses BNIP3 expression to protect against hypoxia-induced cell death. EMBO J, 2011, 30: 3397-3415

142 Guan B, Ma H, Wang Y, et al. Vitreoscilla hemoglobin (VHb) overexpression increases hypoxia tolerance in zebrafish (Danio rerio). Mar Biotechnol (NY), 2011, 13: 336-344

143 Liu Z J. Fish genomics and analytical genetic technologies, with examples of their potential applications in management of fish genetic resources. In: Bartley D M, Harvey B J, Pullin R S V, eds. Workshop on Status and Trends in Aquatic Genetic Resources: a basis for international policy. Food and Agriculture Organization of the United Nations, Rome, 2007. 145-178

144 McAndrew B, Napier J. Application of genetics and genomics to aquaculture development: current and future directions. J Agric Sci, 2010, 149: 143-151

145 Abernathy J W, Peatman E, Liu Z J. Basic aquaculture genetics. SRAC Publication No. 5001. 2010, 1-16

146 Wang Z W, Zhu H P, Wang D, et al. A novel nucleo-cytoplasmic hybrid clone formed via androgenesis in polyploid gibel carp. BMC Res Notes, 2011, 4: 82

147 Liu H Q, Cui S Q, Hou C C, et al. YY supermale generated gynogenetically from XY female in Pelteobagrus fulvidraco (Richardson). Acta Hydrobiol Sin, 2007, 31: 718-725

148 Wang D, Mao H L, Chen H X, et al. Isolation of Y- and X-linked SCAR markers in yellow catfish and application in the production of all-male populations. Anim Genet, 2009, 40: 978-981

Open Access This article is distributed under the terms of the Creative Commons Attribution License which permits any use, distribution, and reproduction in any medium, provided the original author(s) and source are credited. 